\title{
ULTRASOUND-ASSISTED SURFACTANT ENHANCED EMULSIFICATION MICROEXTRACTION METHOD COUPLED WITH GAS CHROMATOGRAPHY-MASS SPECTROMETRY FOR THE DETERMINATION OF SELECTED POLYCYCLIC AROMATIC HYDROCARBONS IN AQUEOUS SAMPLES
}

\author{
(Kaedah Pengekstrakan Mikro Ultrabunyi dengan Bantuan Surfaktan Meningkatkan \\ Pengemulsian Bergabung dengan Kromatografi Gas-Spektrometri Jisim Bagi Penentuan \\ Polisiklik Aromatik Hidrokarbon Terpilih di dalam Sampel Akueus) \\ Siti Farahiyah Ahmad Shater ${ }^{1}$, Noorfatimah Yahaya ${ }^{1}$, Nur Nadhirah Mohamad Zain ${ }^{1}$, Sharlina Mohamad ${ }^{1}$, \\ Farah Wahidah Mohd Hassan ${ }^{1}$, Sazlinda Kamaruzaman ${ }^{2}$, Nor Suhaila Mohamad Hanapi ${ }^{3}$, \\ Mazidatulakmam Miskam ${ }^{4}$ \\ ${ }^{1}$ Integrative Medicine Cluster, Advanced Medical and Dental Institute (AMDI), \\ Universiti Sains Malaysia, Bertam, 13200 Kepala Batas, Penang, Malaysia \\ ${ }^{2}$ Department of Chemistry, Faculty of Science, \\ Universiti Putra Malaysia, 43400 UPM Serdang, Selangor, Malaysia \\ ${ }^{3}$ Faculty of Applied Sciences, \\ Universiti Teknologi MARA, 40450 Shah Alam, Selangor, Malaysia \\ ${ }^{4}$ School of Chemical Sciences, \\ Universiti Sains Malaysia, 11800 Penang, Malaysia \\ *Corresponding author: noorfatimah@usm.my
}

Received: 29 March 2017; Accepted: 20 June 2017

\begin{abstract}
A simple and rapid microextraction method termed as ultrasound-assisted surfactant enhanced emulsification microextraction (UASEME) was developed for the determination of fluoranthene (FLU) and phenanthrene (PHE) in aqueous samples followed by gas chromatography-mass spectrometry (GC-MS). Six important parameters, that affect the extraction efficiency of polycyclic aromatic hydrocarbons (PAHs) were evaluated and the results were as follows; extraction solvent (toluene), volume of extraction solvent $(30 \mu \mathrm{L})$, surfactant (Tween 20$)$, volume of surfactant $(15 \mu \mathrm{L})$, extraction time ( 2 minutes) and with no salt addition. Under the optimum conditions, the method showed good linearity over the concentration range from $1-1000 \mu \mathrm{g} \mathrm{L}{ }^{-1}$ with correlation coefficients $\left(\mathrm{R}^{2} \geq 0.9932\right)$, acceptable limits of detection $\left(0.3 \mu \mathrm{g} \mathrm{L}^{-1}\right)$ and limits of quantification $(1.0 \mu \mathrm{g} \mathrm{L}-1)$ for both analytes. Good relative recovery values, in the range of $91.75-104.1 \%$, were obtained for tap water samples. The relative standard deviations (RSDs) were $1.62-10.32 \%(n=3)$. The proposed method was applied for the determination of FLU and PHE in tap water and sugarcane juices.
\end{abstract}

Keywords: ultrasound-assisted, surfactant, emulsification, polycyclic aromatic hydrocarbons, gas chromatography-mass spectrometry

\section{Abstrak}

Satu kaedah pengekstrakan mikro yang mudah dan cepat disebut kaedah ultrabunyi-dibantu surfaktan diperkuat pengemulsian dibangunkan bagi penentuan fluorantin (FLU) dan fenantrin (PHE) di dalam sampel akueus diikuti oleh kromatografi gasspektrometri jisim (GC-MS). Enam parameter penting, mempengaruhi kecekapan pengekstrakan hidrokarbon aromatik polisiklik 
Siti Farahiyah et al: ULTRASOUND-ASSISTED SURFACTANT ENHANCED EMULSIFICATION

MICROEXTRACTION METHOD COUPLED WITH GAS CHROMATOGRAPHY-MASS

SPECTROMETRY FOR THE DETERMINATION OF SELECTED POLYCYCLIC

AROMATIC HYDROCARBONS IN AQUEOUS SAMPLES

(PAH) telah dinilai dan keputusan adalah seperti berikut; pengekstrakan pelarut (toluena) jumlah pelarut pengekstrakan (30 $\mu \mathrm{L})$, surfaktan (Tween 20), jumlah surfaktan $(15 \mu \mathrm{l})$, masa pengekstrakan (2 minit) dan tanpa tambahan garam. Di bawah keadaan yang optimum, kaedah ini menunjukkan kelinearan baik pada julat kepekatan $1-1000 \mu \mathrm{g} \mathrm{L}^{-1}$ dengan pekali korelasi $\left(\mathrm{R}^{2} \geq\right.$ 0.9932) dan had pengesanan yang diterima $\left(0.3 \mu \mathrm{g} \mathrm{L}^{-1}\right)$ dan had kuantifikasi $\left(1.0 \mu \mathrm{g} \mathrm{L}^{-1}\right)$ untuk kedua-dua analit. Nilai perolehan semula yang baik dalam julat $91.75-104.1 \%$, telah diperoleh bagi sampel air paip. Sisihan piawai relatif (RSDs) adalah $1.62-10.32 \%(n=3)$. Kaedah yang dicadangkan telah digunakan untuk penentuan FLU dan PHE dalam sampel air paip dan jus tebu.

Kata kunci: ultrabunyi-dibantu, surfaktan, pengemulsian, polisiklik aromatik hidrokarbon, kromatografi gas-spektrometri jisim

\section{Introduction}

Polycyclic aromatic hydrocarbons (PAHs) are organic compounds with two or more benzene rings categorized by the European Union (EU) and the US Environmental Protection Agency (US EPA) as priority pollutants due to their mutagenic and carcinogenic properties [1]. PAHs are ubiquitous in the environment and have mainly been found in the process of incomplete combustion of oil spill, fossil fuels, wood and etc [2]. Fluoranthene (FLU) and phenanthrene (PHE) are listed as priority pollutants by the US EPA and the action and risk levels of FLU and PHE are described in the Dutch Government Quality Standards for the assessment soil and water contamination [3]. Since PAH compounds exist at very low concentrations in the environment and the presence of a high level of matrix interferences in samples, the determination of these compounds in environmental samples is complicated. Thus, a fast and effective sample pre-treatment method is critical to eliminate major interferences and enrich the target analytes before instrumental analysis.

Liquid-liquid extraction (LLE) [4] and solid phase extraction (SPE) [4, 5] are conventional sample preparation methods that have been employed for the determination of PAHs. However, these classical pre-concentration methods involve several phase operations with the consumption of large volumes of toxic organic solvent that lead to environment-unfriendly processes [6]. Researchers are devoted to the development of a microextraction method to overcome these problems as it is environmental friendly and consumes a minimum amount of organic solvent. Several microextraction methods have been developed for the determination of PAH compounds including liquid phase microextraction (LPME) [7], static- liquid phase microextraction (S-LPME) [8] and ultrasound assisted emulsification microextraction (UAEME) [9]. Although there are various established analytical methods nowadays, the application of microextraction on sugarcane samples is still unexplored. A micro implementation of liquid-liquid extraction (LLE), namely liquid-phase microextraction (LPME) has become a very popular sample pre-treatment technique because it combines extraction and enrichment of target analytes with a relatively inexpensive cost, is easy to operate and nearly solvent-free [10].

Ultrasonic-assisted emulsification microextraction (UAEME) is developed for the extraction of organic compounds from water samples [11]. This method has proven to be an efficient tool in the formation of the emulsification phase and acceleration of mass transfer between two immiscible phases [12]. A relatively new method is developed using surfactants as the emulsifier in the UAEME method for detection of selected carbamate compounds in water samples [13]. Surfactants are known as surface active agents since they have both hydrophilic and hydrophobic moieties [13]. Due to their amphiphilic structure, they are able to react both in water and immiscible phases and thus can be used as emulsifiers to enhance the dispersion of the water-immiscible phase into the aqueous phase [13]. The newly introduced method incorporated with the surfactant has greatly shortened the time of extraction required due to the effective combination of surfactant and ultrasound radiation [14]. USAEME has been previously employed for the determination of poly-brominated flame retardants in water samples [13] and for determination of PAHs in water samples $[15,16]$. In the UASEME method, the extraction procedure is carried out under the simultaneous actions of ultrasound radiation and surfactant, shortening the time for analysis [13]. Ultrasound radiation leads to the fragmentation of one of the phases, resulting in the rapid emulsification of the mixture [9].USAEME provides very high extraction efficiencies in a short time, since the high contact surface between both liquids facilitates the mass transfer from the sample solution to the extraction solvent [9]. This developed method provides many advantages such as excellent enrichment factors, simplicity, stability, easy to operate, low cost and low consumption of organic solvents [15]. 
In this study, a new microextraction method termed UASEME incorporated with Tween 20 was developed prior to GC-MS determination of FLU and PHE in tap water and sugarcane juice samples. Six parameters were optimized including the type of extraction solvent, type of surfactant, volume of extraction solvent, volume of surfactant, salt addition and extraction time. Based on the results obtained, the proposed method is applicable for the analysis of selected PAHs in aqueous matrices due to its simplicity, efficiency and sensitivity. To the best of our knowledge, there is no paper reported on the determination of FLU and PHE in aqueous matrices using this method.

\section{Materials and Methods}

\section{Chemicals and reagents}

Fluoranthene (FLU) and phenanthrene (PHE) (Figure 1) were obtained from Toronto Research Chemicals INC (Toronto, Canada). HPLC-Grade toluene, n-hexane, iso-octane, and 1-octanol were purchased from QReC Asia Sdn. Bhd. (Selangor, Malaysia). Analytical grade surfactants (Tween 80, Tween 20 and DC193C) were purchased in their chemically pure form from Fisher Scientific (Selangor, Malaysia). Ultrapure water of $18.2 \mathrm{M} \Omega$ was purified by a Sartorious system, model Arium 611 D1 (Stedim Biotech, Gottingen, Germany). Stock standard solutions $\left(1000 \mu \mathrm{g} \mathrm{L}^{-1}\right)$ of FLU and PHE were prepared in a solvent mixture of methanol and acetonitrile (1:1) and stored in the dark at $4{ }^{\circ} \mathrm{C}$. The working standard solutions were prepared daily by the dilution of stock solution in ultrapure water prior to extraction and analysis.

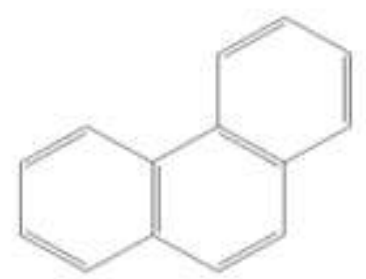

Phenanthrene

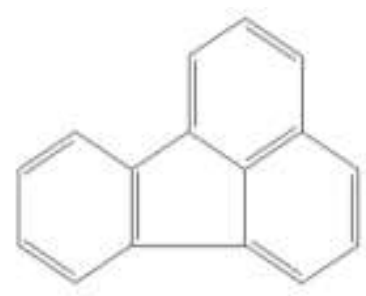

Fluoranthene

Figure 1.2D-structures of selected polycyclic aromatic hydrocarbons

\section{GC-MS operating conditions}

All analyses were performed using Agilent GC system Model 7890A with mass spectrometry analyser Model 5975C (Palto Alto, USA). Helium gas was used with a constant flow rate of $1 \mathrm{~mL} \mathrm{~min}^{-1}$. Splitless injections were performed at $250{ }^{\circ} \mathrm{C}$ and the volume of injection was $1 \mu \mathrm{L}$. The chromatographic condition was carried out on an Agilent HP 5-MS column ( $30 \mathrm{~m} \times 0.25 \mathrm{~mm}$ I.D., $0.25 \mu \mathrm{m}$ film thickness). The oven temperature applied was initially programmed at $150{ }^{\circ} \mathrm{C}$ for 3 minutes. After that, the temperature was raised up to $250{ }^{\circ} \mathrm{C}$ at $10{ }^{\circ} \mathrm{C}$ per minute. The transfer line and ion source temperature were fixed at $280^{\circ} \mathrm{C}$. Data were collected and quantified in the scan of the mass spectrometer analyzer. The retention time of PHE and FLU were recorded under optimized chromatographic conditions at 8.90 and 11.75 minutes, respectively. Electron impact mass spectra were recorded at $70 \mathrm{eV}$ and the detector voltage was set at $1.0 \mathrm{kV}$. The chromatographic data were processed using MSD Chemstation E.01.01 Agilent Technology software.

\section{Samples collection}

The optimized UASEME method was applied to the analysis of aqueous matrices. Tap water samples were obtained from the laboratory in the Integrative Medicine Cluster, Advanced Medical and Dental Institute, Universiti Sains Malaysia, Penang. Sugarcane juice samples were purchased from street vendors and local stores in Kedah and Penang, Malaysia. The sugarcane juice samples were centrifuged for 15 minutes at $3500 \mathrm{rpm}$ prior to extraction. The pellet layer was discarded before the microextraction procedure. The samples were filtered through a $0.45 \mu \mathrm{m}$ Whatman nylon membrane filter to remove unwanted particles and stored in refrigerator $\left(4^{\circ} \mathrm{C}\right)$ prior to use.

\section{Ultrasound-assisted surfactant enhanced emulsification microextraction}

The ultrasound-assisted surfactant enhanced emulsification microextraction (UASEME) procedure is illustrated in Figure 2. Firstly, $15 \mu \mathrm{L}$ of Tween 20 was added into a $10-\mathrm{mL}$ volumetric flask followed by the addition of $30 \mu \mathrm{L}$ toluene. Then, $10 \mathrm{~mL}$ sample solution spiked with PAHs was immediately added into the volumetric flask. Next, the 
Siti Farahiyah et al: ULTRASOUND-ASSISTED SURFACTANT ENHANCED EMULSIFICATION

MICROEXTRACTION METHOD COUPLED WITH GAS CHROMATOGRAPHY-MASS

SPECTROMETRY FOR THE DETERMINATION OF SELECTED POLYCYCLIC

AROMATIC HYDROCARBONS IN AQUEOUS SAMPLES

mixture was sonicated for 2 minutes. After sonication, two immiscible phases were formed and $20 \mu \mathrm{L}$ of the upper layer was collected using a micro syringe. Finally, the clean extract was diluted with $80 \mu \mathrm{L}$ of methanol prior to GC-MS analysis. Quantification for all data was calculated based on the peak area of analytes.

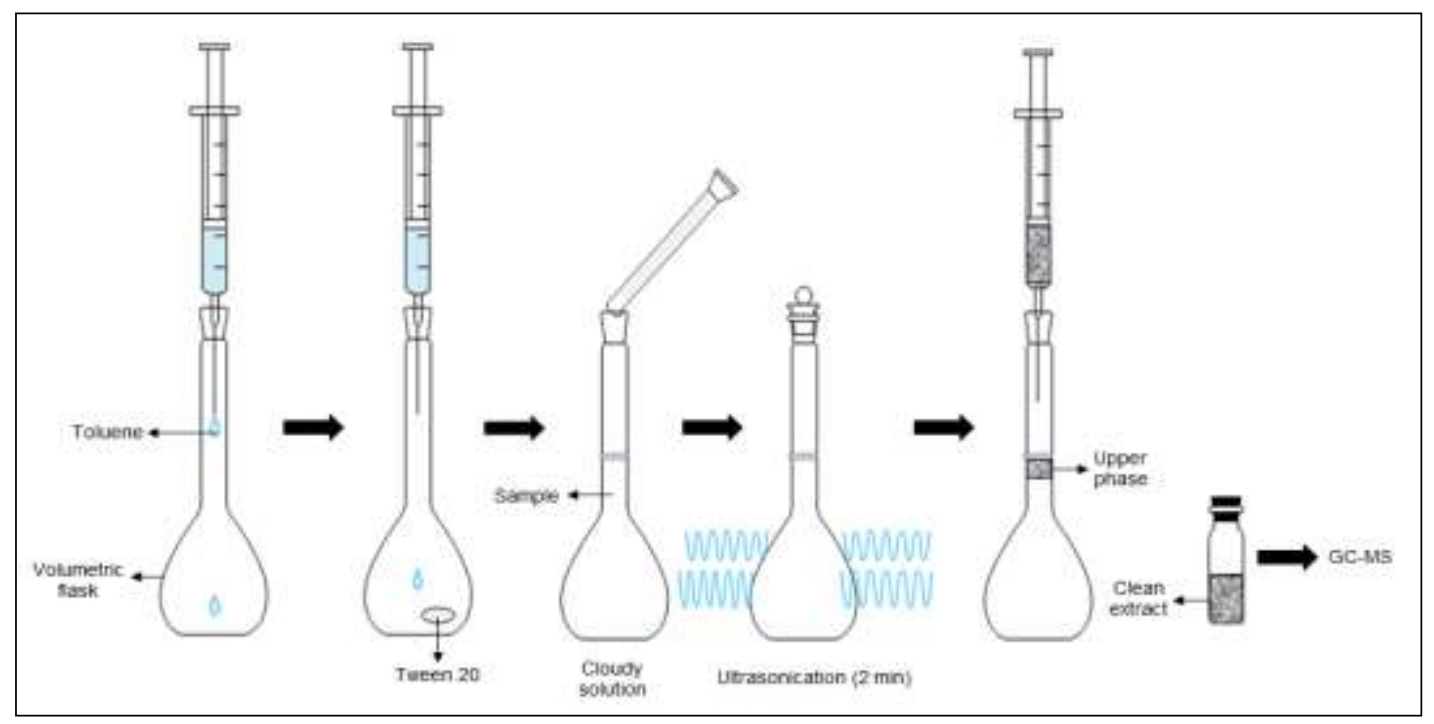

Figure 2. Schematic of UASEME procedure

\section{Optimization of UASEME procedure}

\section{Results and Discussion}

In order to obtain the optimum extraction and detection conditions for FLU and PHE, several parameters that potentially affect the extraction performance of UASEME were thoroughly investigated, namely type and volume of extraction solvent, type and concentration of surfactant, extraction time and salt addition. All optimization parameters were conducted in triplicates using $1000 \mu \mathrm{g} \mathrm{L}^{-1}$ of PHE and FLU spiked in water.

\section{Effect of type and volume of extraction solvent}

A good selection of extraction solvent should meet some important criteria such as (a) less dense than water; (b) low solubility in water; and (c) able to form a stable emulsion system in the presence of an emulsifier after sonication and has the ability to extract the targeted analytes $[12,13]$. In this study, four solvents were tested namely toluene, $\mathrm{n}$-hexane, iso-octane and 1-octanol. The result showed that toluene gave the highest extraction efficiency compared to other solvents (Figure 3a). This might probably due to the lower viscosity of toluene, which leads to a rapid and efficient emulsification process [15]. Thus, toluene was selected as the extraction solvent for subsequent experiments.

To optimize the volume of extraction solvent, different volumes of toluene $(20,25,30,35,40,45,50$, and $55 \mu \mathrm{L})$ were evaluated. The results indicated that the peak areas of all analytes reached maximum when using $30 \mu \mathrm{L}$ of toluene as extraction solvent (Figure 3b). However, the peak areas of all analytes decreased gradually when more volume of toluene was used. This may be due to the dilution effect; as the amount of extraction solvent is increased, the volume of the floating phase (upper phase) will also increase [17]. Therefore, $30 \mu \mathrm{L}$ of toluene as extraction solvent was used for further analysis. 

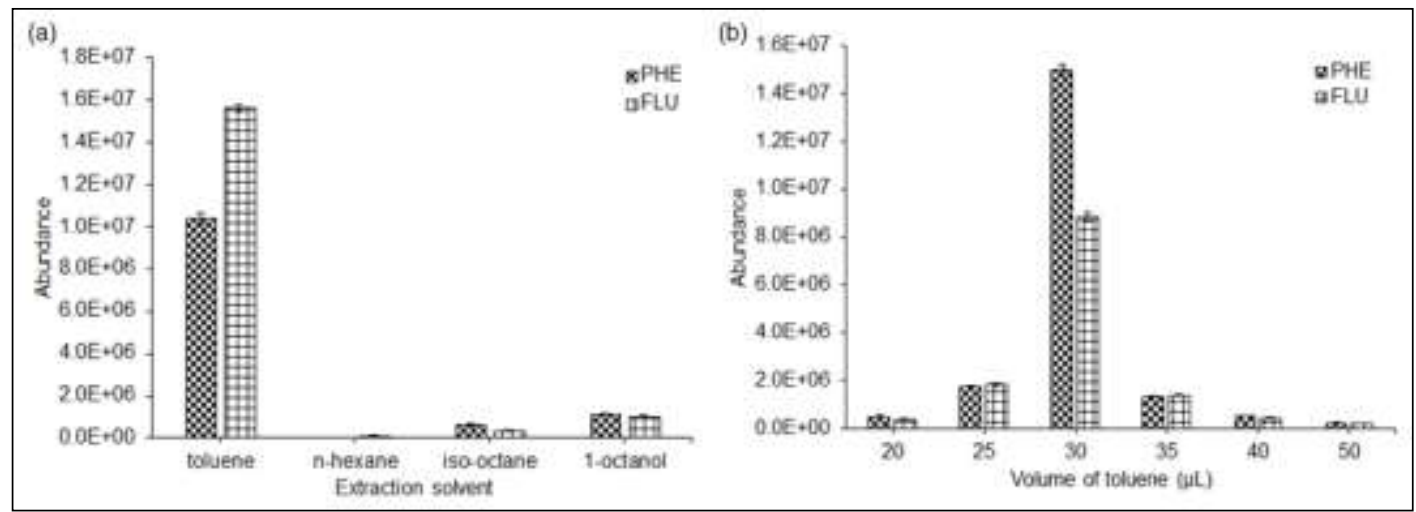

Figure 3. Effect of extraction solvent (a) and volume of toluene (b) on UASEME methods on the extraction of PHE and FLU from spiked water ( $\mathrm{n}=3$ in each case)

\section{Effect of type and volume of surfactant}

The selection of a suitable surfactant is very crucial in order to obtain higher extraction efficiency for the targeted analytes. Under ultrasound radiation, the surfactant enhances the rate of emulsification process between the waterimmiscible extraction solvent and aqueous solution. Upon completion of emulsification process, the extraction solvent is dispersed as fine droplets in the sample solution, which accelerate the mass transfer process of the analytes from the aqueous phase to the organic phases. A suitable hydrophilic-lipophilic balance (HLB) is the primary criterion for the selection of surfactant. The effects of three non-ionic surfactants (Tween 20, Tween 80 and DC193C) on the extraction efficiency of UASEME were investigated. The results showed that Tween 20 gave the highest extraction efficiency for both analytes compared to without the use of surfactant, DC193C and Tween 80 (Figure 4a). The occurrence of this phenomenon may be due to the hydrophobic properties of Tween 20 which interact ideally with the non-polar FLU and PHE compounds. A strong hydrophobic interaction between Tween 80 and PAHs contributed to less extraction efficiency of analytes toward the extraction solvent as indicated by the suppression of GC-MS chromatographic responses.

The volume of surfactant is important in the UASEME method as it will affect the mass transfer rate of the analytes. The effect of Tween 20 amount used was investigated by varying its volume from 0 to $25 \mu \mathrm{L}$. Based on the results obtained (Figure $4 \mathrm{~b}$ ), the extraction efficiency began to decrease as the volume of Tween 20 increased. This was probably due to the fractionation of the analytes which was incorporated into the micelle when the surfactant concentration was higher than the CMC, thus increasing the solubility of analytes in the sample solution [18]. Therefore, $15 \mu \mathrm{L}$ of Tween 20 was used in the subsequent extractions.
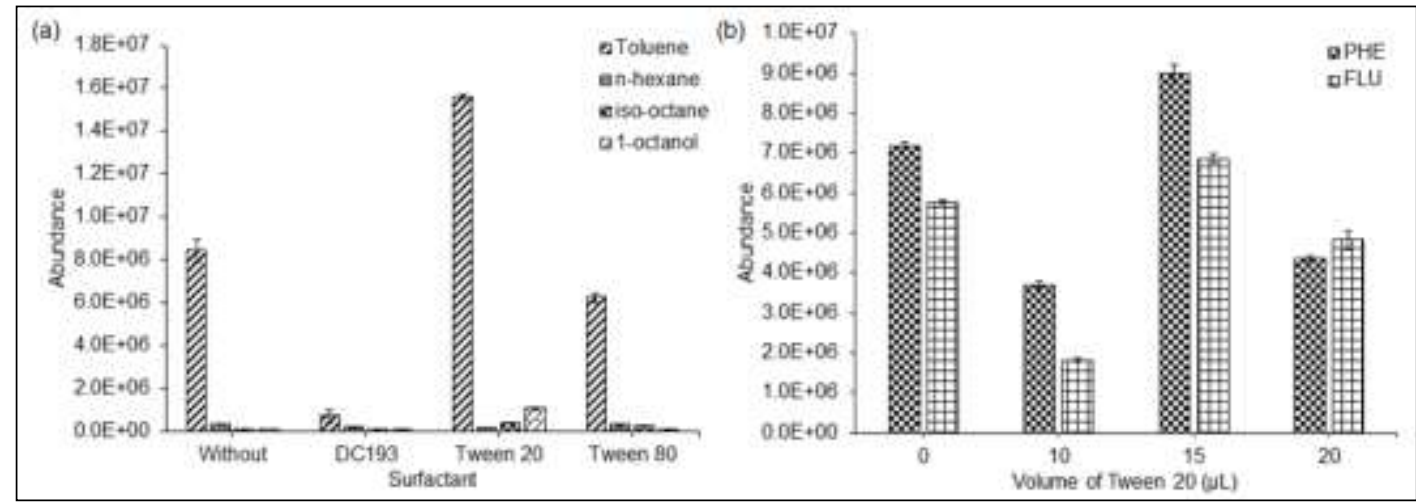

Figure 4. Effect of surfactant (a) and volume of Tween 20 (b) on UASEME methods on the extraction of PHE and FLU from spiked water sample $(\mathrm{n}=3$ in each case) 
Siti Farahiyah et al: ULTRASOUND-ASSISTED SURFACTANT ENHANCED EMULSIFICATION

MICROEXTRACTION METHOD COUPLED WITH GAS CHROMATOGRAPHY-MASS

SPECTROMETRY FOR THE DETERMINATION OF SELECTED POLYCYCLIC

AROMATIC HYDROCARBONS IN AQUEOUS SAMPLES

\section{Effect of extraction time and salt addition}

In this study, the interval time from the beginning of the emulsification to the moment before the injection into the vial is known as the ultrasound extraction time. The effect of extraction time in this method was studied over the range from 0 to 5 minutes with other experimental conditions kept constant (Figure 5a). The results showed that the peak area increased continuously from 0 to 2 minutes of extraction time. It revealed that the contact surface between the extraction solvent and aqueous sample was infinitely larger [14]. However, when the extraction time was prolonged to 3 minutes, the extraction efficiency of the analytes decreased. This occurrence was probably due to the longer sonication time which produced heat to the sample vial and caused the analytes' degradation [19]. Hence, 2 minutes was used as the optimum extraction time in the UASEME method.

Generally, the addition of salt into the sample solution may reduce the solubility of polar analytes and enhance their partitioning into the extraction solvent or organic phase. The effect of the $\mathrm{NaCl}$ addition on the UASEME method's efficiency was evaluated and studied in the range from 0 to $12 \%(\mathrm{w} / \mathrm{v})$. The results showed that there was no significant increment with the addition of salt during UASEME (Figure 5b) due to the relatively non-polar characteristics of FLU and PHE. Hence, no salt was added in the subsequent UASEME method analysis.

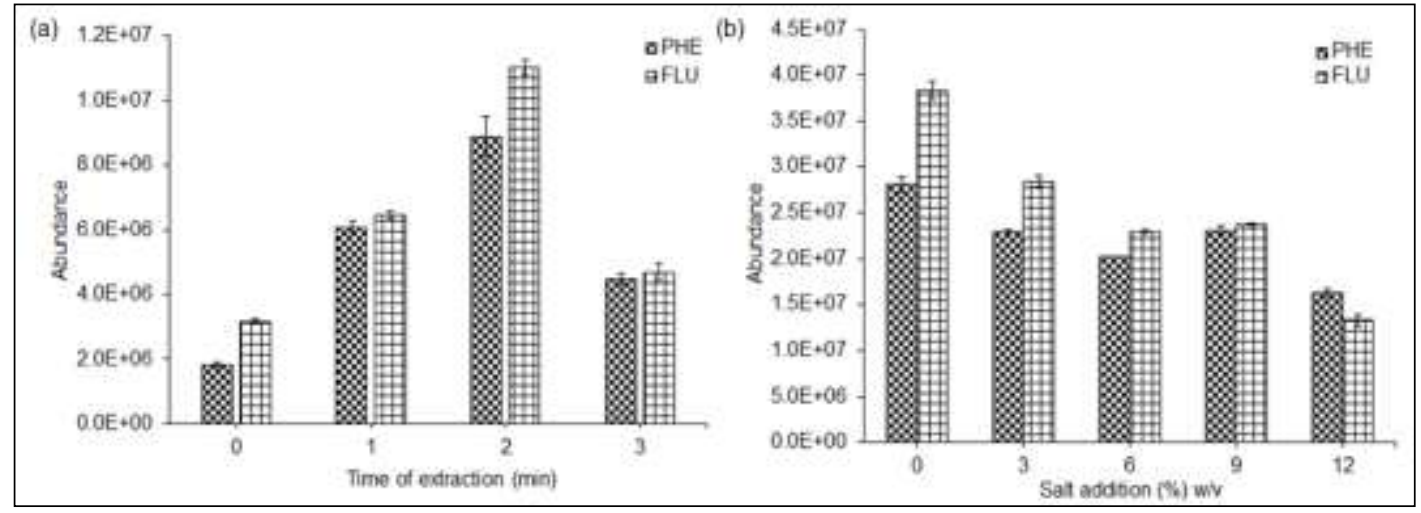

Figure 5. Effect of extraction time (a) and salt addition (b) on UASEME methods on the extraction of PHE and FLU from spiked water sample $(n=3$ in each case)

\section{Method validation}

The analytical performance of the proposed UASEME method was evaluated in terms of its linearity, limits of detection (LODs), limits of quantification (LOQs), precision and recovery under the optimized extraction conditions. Method validation was carried out based on the ICH Harmonised Tripartite Guideline [20]. The calibration curves were plotted in the concentration range between 1 to $1000 \mu \mathrm{g} \mathrm{L}^{-1}$ using at least five spiked concentrations in distilled water. Good linearity was observed for PHE and FLU with the coefficient of determination, $\mathrm{R}^{2}$ of 0.9932 and 0.9968 , respectively (Table 1). LODs were calculated as three times the signal-tonoise ratio $(\mathrm{S} / \mathrm{N}=3)$ and LOQs were measured as ten times the signal-to-noise ratio $(\mathrm{S} / \mathrm{N}=10)$. The LODs and LOQs for PHE and FLU obtained in this study were 0.3 and $1.0 \mu \mathrm{g} \mathrm{L}^{-1}$, respectively. Under the optimized UASEME conditions, the enrichment factors (EFs) of 21.8 and 30.6 were obtained for PHE and FLU, respectively. EF was calculated using the following Equation 1:

$$
\mathrm{EF}=\mathrm{C}_{1} / \mathrm{C}_{0}
$$

where $\mathrm{C}_{1}$ and $\mathrm{C}_{0}$ are the final concentrations of analytes found in the clean extract and initial concentration in the original sample solution, respectively. 
Table 1. Validation data of UASEME method for selected polycyclic aromatic hydrocarbons in spiked water samples

\begin{tabular}{ccccccc}
\hline Analyte & $\begin{array}{c}\text { Linear Range } \\
\left(\boldsymbol{\mu g} \mathbf{L}^{-\mathbf{1}}\right)\end{array}$ & Linear Equation & $\mathbf{R}^{\mathbf{2}}$ & $\begin{array}{c}\text { LOD } \\
\left(\boldsymbol{\mu g ~ \mathbf { ~ L } ^ { - 1 } )}\right.\end{array}$ & $\begin{array}{c}\mathbf{L O Q} \\
\left(\boldsymbol{\mu g ~ \mathbf { ~ L } ^ { - 1 }}\right)\end{array}$ & $\mathbf{E F}$ \\
\hline PHE & $1-1000$ & $\mathrm{y}=15419 \mathrm{x}+13043$ & 0.9932 & 0.3 & 1.0 & 21.8 \\
FLA & $1-1000$ & $\mathrm{y}=5609.9 \mathrm{x}-34604$ & 0.9968 & 0.3 & 1.0 & 30.6 \\
\hline
\end{tabular}

The analytical characteristics of the proposed UASEME method were compared with other reported methods for the analysis of PAHs in water samples (Table 2). Although the developed method produced a lower sensitivity of analytes compared to most methods used for PAHs determination, the use of $30 \mu \mathrm{L}$ of toluene and $15 \mu \mathrm{L}$ of Tween 20 in UASEME is more environmentally friendly and beneficial as an alternative microextraction method for the analysis of PAHs in aqueous samples. In addition, the proposed method is rapid and the extraction process can be accomplished within $5 \mathrm{~min}$, which is useful for routine analyses of PAHs.

Table 2. Comparison of UASEME method with other previously reported methods

\begin{tabular}{llcccc}
\hline Instrument & Sample Preparation & $\begin{array}{c}\text { LOD } \\
\left(\boldsymbol{\mu g} \mathbf{~ L}^{-\mathbf{1}}\right)\end{array}$ & $\begin{array}{c}\text { Precision } \\
(\text { RSD })\end{array}$ & $\begin{array}{c}\text { Recovery } \\
(\boldsymbol{\%})\end{array}$ & References \\
\hline GC-MS $^{\mathrm{a}}$ & UASEME $^{\mathrm{d}}$ & 0.3 & $1.62-10.32$ & $91.75-104.1$ & This work \\
GC-MS & SPME $^{\mathrm{e}}$ & $0.001-0.029$ & $<20$ & - & {$[21]$} \\
HPLC-FLD $^{\mathrm{b}}$ & SBSE $^{\mathrm{f}}$ & $0.0002-0.0015$ & $3.2-12.8$ & $60.1-86.8$ & {$[22]$} \\
GC-MS & USAEME $^{\mathrm{g}}$ & $0.001-0.036$ & $<8$ & $>92$ & {$[16]$} \\
GC-MS & AF-LPME $^{\mathrm{h}}$ & $0.01-0.04$ & $6.1-9.2$ & $92.9-104.7$ & {$[23]$} \\
GC-FID $^{\mathrm{c}}$ & HSME $^{\mathrm{i}}$ & $4-41$ & $0.7-19.5$ & - & {$[24]$} \\
\hline
\end{tabular}

a Gas chromatography-mass spectrometry,

b High performance liquid chromatography-fluorescence detection,

c Gas chromatography-flame ionization detection,

d Ultrasound-assisted surfactant enhanced emulsification microextraction,

e Solid-phase microextraction,

f Stir bar sorptive extraction,

g Ultrasound-assisted emulsification-microextraction,

h Agarose film liquid phase microextraction,

i Headspace solvent microextraction

\section{Real sample analysis}

To evaluate the applicability of the proposed method, the procedure was performed as an analysis of PAHs in one tap water and nine sugarcane juice samples. Analyses of these samples were conducted under the optimum conditions of UASEME. From the blank analyses, no PHE and FLU were detected in all samples. The non-spiked and spiked tap water samples were analysed in triplicate and the typical chromatograms of blank and spiked samples at $100 \mu \mathrm{g} \mathrm{L}^{-1}$ are shown in Figure 6. The accuracy of the developed method was determined by spiking analytes at three different concentration levels $\left(1,50\right.$ and $\left.100 \mu \mathrm{g} \mathrm{L}^{-1}\right)$ into the tap water samples. The relative recovery was calculated as the percentage of mean values of the extracted PAHs peak area (triplicates) against the peak area of PAHs derived from the calibration curve. Table 3 shows a recovery of $91.75-104.1 \%$ for both analytes with RSDs of $1.62-10.32 \%$. The obtained results demonstrated that the proposed UASEME method is applicable for low and high concentrations of PAHs in aqueous matrices. 
Siti Farahiyah et al: ULTRASOUND-ASSISTED SURFACTANT ENHANCED EMULSIFICATION

MICROEXTRACTION METHOD COUPLED WITH GAS CHROMATOGRAPHY-MASS

SPECTROMETRY FOR THE DETERMINATION OF SELECTED POLYCYCLIC

AROMATIC HYDROCARBONS IN AQUEOUS SAMPLES

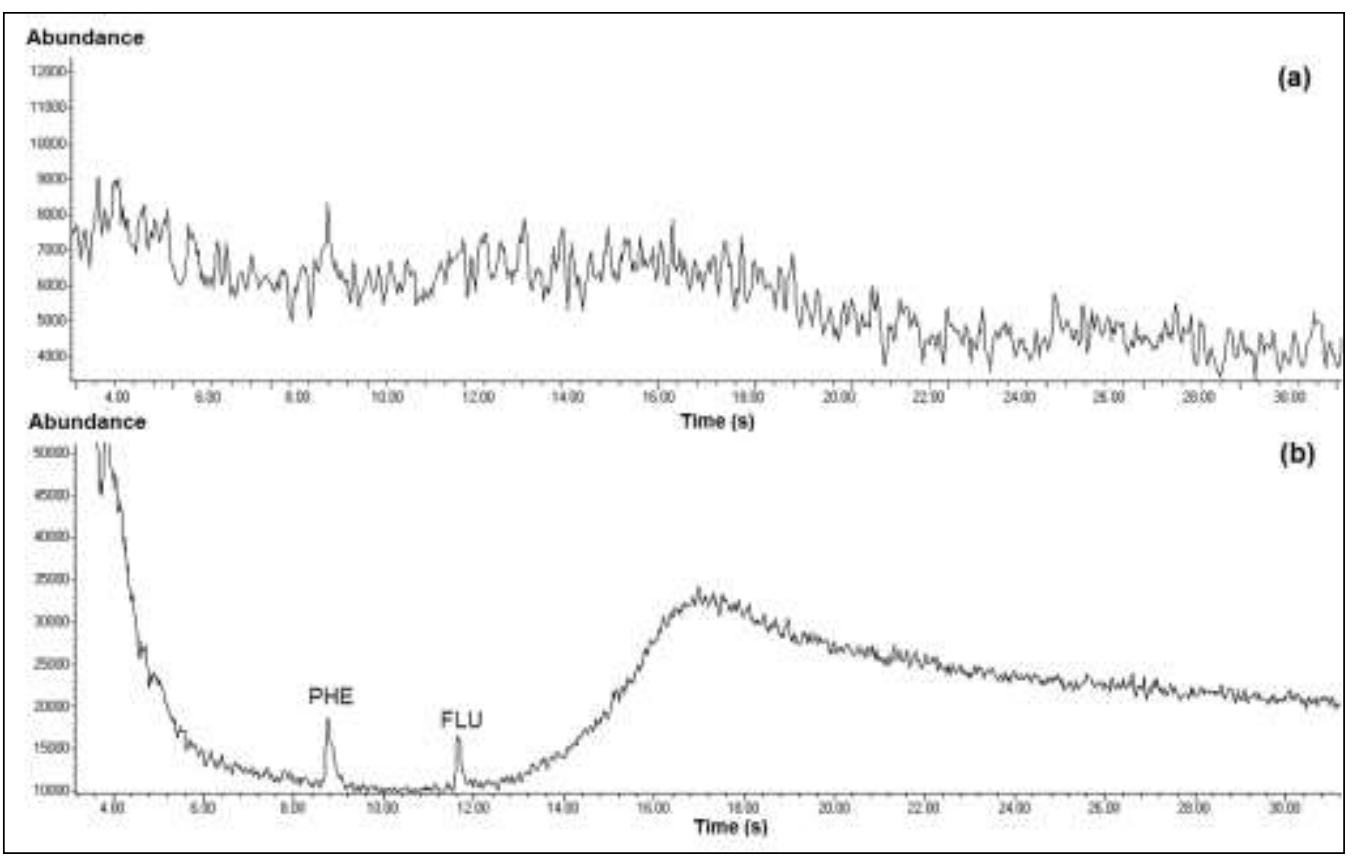

Figure 6. GC-MS chromatograms of PAHs obtained by UASEME under optimized conditions (a) blank tap water (b) spiked tap water at $100 \mu \mathrm{g} \mathrm{L}^{-1}$

Table 3. Recoveries obtained in determination of phenanthrene and fluoranthene in spiked tap water samples by UASEME

\begin{tabular}{lcccc}
\hline Analyte & $\begin{array}{c}\text { Spiked level } \\
\left(\boldsymbol{\mu g} \mathbf{L}^{-\mathbf{1}}\right)\end{array}$ & $\begin{array}{c}\text { Intraday Precision } \\
(\boldsymbol{\%} \mathbf{R S D}),(\mathbf{n}=\mathbf{3})\end{array}$ & $\begin{array}{c}\text { Concentration Found } \\
\left(\boldsymbol{\mu} \mathbf{g ~ L}^{-1}\right)\end{array}$ & $\begin{array}{c}\text { Recovery }(\%) \\
(\mathbf{n}=\mathbf{3})\end{array}$ \\
\hline PHE & 0 & - & $\mathrm{nd}$ & - \\
& 1 & 6.24 & 0.92 & 91.75 \\
& 50 & 5.71 & 48.84 & 97.67 \\
& 100 & 1.62 & 99.5 & 99.50 \\
FLA & 0 & - & $\mathrm{nd}$ & - \\
& 1 & 10.32 & 0.94 & 93.88 \\
& 50 & 9.63 & 49.80 & 99.59 \\
& 100 & 5.08 & 104.1 & 104.1 \\
\hline
\end{tabular}

nd: not detected

\section{Conclusion}

In brief, the results indicated that the UASEME method can be used as a simple and efficient sample preparation technique for trace analysis of PAHs in aqueous samples prior to GC-MS analysis. This method also uses a minimum amount of extraction solvent and surfactant for each extraction. Therefore, the new UASEME method can be potentially used as an alternative 'green' microextraction for the detection of PAHs in aqueous matrices. Future investigations can be focused on the combination of the developed method with other microextraction methods such as dispersive micro-solid phase extraction and magnetic solid phase extraction to improve the sensitivity and detection limits of the studied analytes. 


\section{Acknowledgements}

The authors gratefully acknowledge Universiti Sains Malaysia and the Ministry of Education Malaysia for financial support through the Short-Term Grant (304.CIPPT.6313197) and Fundamental Research Grant Scheme (FRGS 203.CIPPT.6711484).

\section{References}

1. Rezvani-Eivari, M., Amiri, A., Baghayeri, M. and Ghaemi, F. (2016). Magnetized graphene layers synthesized on the carbon nanofibers as novel adsorbent for the extraction of polycyclic aromatic hydrocarbons from environmental water samples. Journal of Chromatography A, 1465: 1 - 8.

2. Wu, Y., Xia, L., Chen, R. and Hu, B. (2008). Headspace single drop microextraction combined with HPLC for the determination of trace polycyclic aromatic hydrocarbons in environmental samples. Talanta, 74 (4): 470 477.

3. Hossain, M. A., Yeasmin, F., Mizanur Rahman, S. M. and Rana, M. S. (2016). Gas chromatograph-mass spectrometry determination of carcinogenic naphthalene, anthracene, phenanthrene and fluorene in the Bangsai river water of Bangladesh. Arabian Journal of Chemistry, 9: 109 - 113.

4. Caruso, M. and Alaburda, J. (2009). Optimization of the benzo (A) pyrene determination procedure in cachaça. Journal of the Brazilian Chemical Society, 20(3): 502 - 508.

5. Da Porto, C. and Moret, S. (2007). Comparison of polycyclic aromatic hydrocarbons (PAHs) between smoked marc spirits and whiskies. Food and Chemical Toxicology, 45(10): 2069 - 2071.

6. Hosseini, M. H., Rezaee, M., Mashayekhi, H. A., Akbarian, S., Mizani, F. and Pourjavid, M. R. (2012). Determination of polycyclic aromatic hydrocarbons in soil samples using flotation-assisted homogeneous liquid-liquid microextraction. Journal of Chromatography A, 1265: 52 - 56.

7. Reza, M., Zanjani, K., Yamini, Y., Shariati, S. and Ake, J. (2007). A new liquid-phase microextraction method based on solidification of floating organic drop. Analytica Chimica Acta, 585(2): 286 - 293.

8. Hou, L. and Lee, H. K. (2002). Application of static and dynamic liquid-phase microextraction in the determination of polycyclic aromatic hydrocarbons. Journal of Chatomatography A, 976(1-2): 377 - 385.

9. Cacho, J. I, Campillo, N., Viñas, P. and Hernández-córdoba, M. (2016). Evaluation of the contamination of spirits by polycyclic aromatic hydrocarbons using ultrasound-assisted emulsification microextraction coupled to gas chromatography - mass spectrometry. Food Chemistry, 190: 324 - 330.

10. Wang, Y., Kwok, Y. C., He, Y. and Lee, H. K. (1998). Application of dynamic liquid-phase microextraction to the analysis of chlorobenzenes in water by using a conventional microsyringe. Analytical Chemistry, 70 (21): 4610 - 4614.

11. Regueiro, J., Llompart, M., Garcia-Jares, C., Garcia-Monteagudo, J. C. and Cela, R. (2008). Ultrasoundassisted emulsification-microextraction of emergent contaminants and pesticides in environmental waters. Journal of Chromatography A, 1190 (1-2): 27 - 38.

12. Fontana, A. R., Wuilloud, R. G., Martínez, L. D. and Altamirano, J. C. (2009). Simple approach based on ultrasound-assisted emulsification-microextraction for determination of polibrominated flame retardants in water samples by gas chromatography-mass spectrometry. Journal of Chromatography A, 1216 (1): 147 - 153.

13. Wu, Q., Chang, Q. and Wu, C. (2010). Ultrasound-assisted surfactant-enhanced emulsification microextraction for the determination of carbamate pesticides in water samples by high performance liquid chromatography. Journal of Chromatography A, 1217(11): 1773 - 1778.

14. Veyrand, B., Brosseaud, A. and Sarcher, L. (2013). Development of a novel ultrasound-assisted surfactantenhanced emulsification microextraction method and its application to the analysis of eleven polycyclic aromatic hydrocarbons at trace levels in water. Journal of Chromatography A, 391(2): 363 - 393.

15. Saleh, A., Yamini, Y., Faraji, M., Rezaee, M. and Ghambarian, M. (2009). Ultrasound-assisted emulsification microextraction method based on applying low density organic solvents followed by gas chromatography analysis for the determination of polycyclic aromatic hydrocarbons in water samples. Journal of Chromatography A, 1216(39): 6673 - 6679.

16. Ozcan, S., Tor, A. and Aydin, M. E. (2010). Determination of polycyclic aromatic hydrocarbons in waters by ultrasound-assisted emulsification-microextraction and gas chromatography-mass spectrometry. Analytica Chimica Acta, 665(2): 193 - 199. 
Siti Farahiyah et al: ULTRASOUND-ASSISTED SURFACTANT ENHANCED EMULSIFICATION

MICROEXTRACTION METHOD COUPLED WITH GAS CHROMATOGRAPHY-MASS

SPECTROMETRY FOR THE DETERMINATION OF SELECTED POLYCYCLIC

AROMATIC HYDROCARBONS IN AQUEOUS SAMPLES

17. Sanagi, M. M., Abbas, H. H., Ibrahim, W. A. W. and Aboul-Enien, H. Y. (2012). Dispersive liquid-liquid microextraction method based on solidification of floating organic droplet for the determination of triazine herbicides in water and sugarcane samples. Food Chemistry, 133(2): 557 - 562.

18. Tseng, W., Chen, P. and Huang, S. (2014). Optimization of two different dispersive liquid - liquid microextraction methods followed by gas chromatography - mass spectrometry determination for polycyclic aromatic hydrocarbons (PAHs) analysis in water. Talanta, 120: 425 - 432.

19. Mukdasai, S., Thomas, C. and Srijaranai, S. (2014). Two-step microextraction combined with high performance liquid chromatographic analysis of pyrethroids in water and vegetable samples. Talanta, 120: 289 - 296.

20. ICH Harmonised Tripartite Guideline Validation of Analytical Procedures. (1994). Text and Methodology. https://www.ich.org/fileadmin/Public_Web_Site/ICH_Products/Guidelines/Quality/Q2_R1/Step4/Q2_R1_Gui deline.pdf [Access online 20 January 2015].

21. King, A. J., Readman, J. W. and Zhou, J. L. (2004). Determination of polycyclic aromatic hydrocarbons in water by solid-phase microextraction-gas chromatography-mass spectrometry. Analytica Chimica Acta, 523(2): 259 - 267.

22. Bourdat-Deschamps, M., Daudin, J. J. and Barriuso, E. (2007). An experimental design approach to optimise the determination of polycyclic aromatic hydrocarbons from rainfall water using stir bar sorptive extraction and high performance liquid chromatography-fluorescence detection. Journal of Chromatography A, 1167(2): 143 153.

23. Sanagi, M. M., Loh, S. H., Wan Ibrahim, W. A., Hasan, M. N. (2012). Agarose film liquid phasemicroextraction combined with gas chromatography-mass spectrometry for the determination of polycyclic aromatic hydrocarbons in water. Journal of Chromatography A, 1262: 43 - 48.

24. Shariati-Feizabadi, S., Yamini, Y. and Bahramifar, N. (2003). Headspace solvent microextraction and gas chromatographic determination of some polycyclic aromatic hydrocarbons in water samples. Analytica Chimica Acta, 489(1): 21 - 31 . 